\title{
ÉTIENNE GILSON LEITOR DE HENRIQUE DE GAND
}

Gustavo Barreto Vilhena de Paiva*

Étienne Gilson foi um dos principais responsáveis pelo estabelecimento dos estudos sobre história da filosofia medieval no século XX. É bem conhecido o fato de que ele dedicou dissertações inteiras àqueles autores que ele tomava como os principais na filosofia medieval. Por isso mesmo, já diz muito o fato de ele não haver dedicado uma tal dissertação a um pensador como Henrique de Gand. Por que, então, se voltar para a leitura que ele possui deste último? Isso vale, parece-me, porque as diversas e curtas exposições que Gilson produz acerca do pensamento de Henrique de Gand apontam para uma clara evolução na sua leitura deste autor e, mais do que isso, para um paulatino aumento da importância atribuída à obra de Henrique de Gand nas narrativas da história da filosofia medieval sucessivamente propostas por Gilson na primeira edição de La philosophie au moyen âge (1922), na segunda edição (1944) da mesma obra e, enfim, no seu History of Christian Philosophy (1955). Neste trabalho, pretendo avaliar cuidadosamente essas diferentes leituras da obra de Henrique de Gand fornecidas por Gilson, buscando compreender as razões que levaram este último a modificar sua leitura daquele primeiro.

Ente; intelecção; metafísica; Étienne Gilson; Henrique de Gand.

I. O objetivo deste trabalho é, em poucas palavras, compreender a leitura proposta por Étienne Gilson (1884-1978) da obra de Henrique de Gand (a. 1240-1293), dito o Doutor Solene. Este último, embora não seja muito conhecido hoje, foi um dos principais mestres de teologia em atividade na Universidade de Paris no último quarto do século XIII. Ora, Gilson dedicou pelo menos uma dissertação a cada autor tardo-antigo ou medieval que lhe parecesse fundamental para a história da filosofia escolástica. Assim, o primeiro passo em nosso estudo já deve ser notar que Gilson não dedicou qualquer livro a Henrique de Gand - não lhe dedicou, tampouco, um único artigo que fosse... Em outras palavras, o Doutor Solene não the aparecia como um autor fundamental para a historiografia da filosofia. Daí se torna claro que a leitura de Henrique não foi, na obra de Gilson, um elemento fundamental como a leitura de Tomás de Aquino; não foi, sequer, um passo relevante, como a leitura de Pedro Abelardo, Heloisa ou João Duns Escoto ${ }^{1}$. Por outro lado, a interpretação dada por Gilson à obra de

\footnotetext{
* Doutorando no Depto. de Filosofia da USP e bolsista CAPES.
} 
Henrique de Gand é claramente tributária do desenvolvimento de sua própria filosofia e, mais precisamente, do papel central que a metafísica nela adquire a partir de 1930. A seguir, farei uma rápida exposição do papel da metafísica na filosofia de Gilson; em seguida, poderemos ver como sua interpretação da obra de Henrique de Gand acompanhou as modificações de sua filosofia.

II. O pensamento de Étienne Gilson surge, parece-me, como um elemento desconcertante para aquele que o considera hoje. Em primeiro lugar, é notável a enorme influência exercida pela sua obra na historiografia da filosofia produzida atualmente, em particular no que diz respeito à história da filosofia tardo-antiga, medieval e do início da modernidade. Porém, esse estudo de caráter histórico (que constitui, para os leitores atuais, o seu legado mais importante) não era, para o próprio Gilson, o principal. Antes, a história da filosofia the fornecia as bases para a reflexão sobre outros temas mais fundamentais de seu pensamento. Ou seja, quando lemos Gilson como historiador da filosofia medieval estamos, de fato, alçando a objeto central de sua obra algo que não lhe servia senão de ponto de partida. Esse papel basilar da história da filosofia na produção do pensamento filosófico fica claro em uma obra como The Unity of Philosophical Experience (1937 [1999³]): nesta, Gilson procura abstrair de uma longa narrativa da história da filosofia do século XII em diante algumas regras filosóficas gerais, dentre as quais a centralidade da metafísica para o pensamento filosófico. Mas voltaremos a isso adiante... Aqui, importa notar que a história da filosofia não é um tema central para Gilson e, não obstante, a relação entre filosofia e história da filosofia se mostra um complexo elemento de sua reflexão.

Essa, porém, não é a única tensão que transparece em sua obra. Com efeito, mais fundamental do que a tensão entre filosofia e história da filosofia para seu pensamento é aquela entre filosofia e religião. Isso ocorre porque Gilson pretendia adotar uma filosofia precisa, a saber: uma filosofia cristã - philosophie chrétienne (cf. GILSON, 1960 [2005²], pp. 157-212) ${ }^{2}$. Ora, o problema de se defender uma filosofia cristã está na difícil tarefa de reunir em um mesmo corpo de pensamento a filosofia, que se quer fundamentalmente racional, e uma religião precisa, o cristianismo (no caso de Gilson, católico), que tem por base a fé. Gilson, decerto, não deseja abrir mão de nenhum dos dois - razão ou fé. Pelo contrário, ele vê

E-mail: gustavo.barreto.paiva@usp.br.

${ }^{1}$ Cf., por exemplo, GILSON, 1938 [1997³] e 1952 [2005²].

${ }^{2}$ Acerca do complexo desenvolvimento da noção de philosophie chrétienne na obra de Étienne Gilson, cf. VIGNAUX, 1987, pp. 9-56. 
na filosofia cristã precisamente uma oportunidade de conjugar ambos: "a filosofia cristã é, portanto, o uso que o cristão faz da especulação filosófica no seu esforço de conquistar a inteligência de sua fé" (op. cit, p. 177). E, no entanto, esta última é também aquilo que guia a filosofia cristã (op. cit., p. 212) - "em uma tal síntese, tudo parte da fé e a ela retorna" (op. cit., p. 194). A filosofia cristã é, assim, uma síntese de um elemento racional e uma fé no cristianismo católico, pela qual se torna possível pesquisar aquilo em que se acredita pela fé, buscando a compreensão racional desse conteúdo de maneira a reforçar aquela fé de que se partia.

Que a filosofia cristã a que Gilson se refere é, sobretudo, católica se torna claro quando notamos que toda essa descrição da 'filosofia cristã' tem por base textual a encíclica Aeterni Patris, publicada pelo papa Leão XIII em $1879^{3}$. De fato, o próprio Gilson apresenta a noção de filosofia cristã a partir de uma cuidadosa interpretação dessa encíclica no seu livro Le philosophe et la théologie $\left(1960\left[2005^{2}\right]\right)$, de onde retiramos as duas citações do parágrafo anterior. Em particular, no nono capítulo dessa obra, se mostra como a Aeterni Patris elabora a noção de 'filosofia cristã' tal como a descrevemos há pouco. Leão XIII, porém, dá mais um passo e aponta aquele autor que deve ser tomado como a base doutrinal desse pensamento, nomeadamente: Tomás de Aquino (1225-1274). É interessante notar que, tanto para afirmar a importância da reflexão filosófica no cristianismo como para constatar a centralidade de Tomás de Aquino nessa filosofia, Leão XIII se vale da enumeração, primeiro, dos autores tardo-antigos e alto-medievais que pretenderam produzir uma reflexão racional tendo como ponto de partida a fé cristã (LEÃO XIII, 1882, pp. iii-xi) e, em seguida, dos autores e documentos eclesiásticos que apontaram Tomás de Aquino como autor central na reflexão sobre a fé cristã e, em particular, católica (op. cit., pp. xi-xii) ${ }^{4}$. Em outras palavras, Leão XIII se vale, nos dois casos, do argumento bem católico da tradição da Igreja. Dessa maneira, Gilson lê na Aeterni Patris, antes de tudo, uma defesa da possibilidade de uma filosofia cristã e uma exortação a que seu desenvolvimento tenha por base o pensamento de Tomás de Aquino. Em um segundo momento, entretanto, fica igualmente claro pela encíclica que a história da filosofia é de suma importância para o estabelecimento da centralidade de Tomás de Aquino na filosofia cristã.

Como vimos há pouco, a filosofia cristã é uma elaboração racional que parte da fé e retorna a ela. Assim, é preciso admitir que o início dessa filosofia - aquilo em que se tem fé, a saber, Deus - é imutável; a própria filosofia cristã, porém, como acabamos de notar, possui

\footnotetext{
${ }^{3}$ Sobre a importância da Aeterni Patris na obra de Gilson, cf. BOURKE, 1979.

${ }^{4}$ Cf. tb. GILSON, 1960 [2005²], p. 176.
} 
claramente uma história que, aliás, aponta para a centralidade de Tomás de Aquino para a reflexão filosófica. Nas palavras de Gilson, "a filosofia cristã é uma história que se desenrola a partir de um termo imutável, situado fora do tempo e, por isso, sem história" (GILSON, $1960\left[2005^{2}\right]$, p. 208). Com isso, Gilson realiza um movimento bem interessante em seu pensamento: dizíamos no início que havia duas tensões em sua obra, a saber, aquela entre filosofia e história da filosofia e aquela entre filosofia e religião. Podemos ver agora que Gilson busca unificar essas tensões em um único problema, afirmando que a fé religiosa diz respeito a algo que está para além da história e a filosofia elaborada racionalmente se dá necessariamente na história. Nesse caso, a filosofia cristã é uma tentativa que evolui historicamente de se compreender o conteúdo imutável e sem história da fé. Essa filosofia cristã histórica encontrou seu ápice em Tomás de Aquino, embora algo de novo possa vir a surgir (op. cit., pp. 210-1)...

Com essas observações fica bem claro o porquê de uma grande parte da obra de Gilson ser voltada para a história da filosofia: é preciso provar a centralidade de Tomás de Aquino nessa história! Para tanto, a história narrada por Gilson se volta, no desenvolvimento de seu pensamento, para a metafísica como um fio condutor. Assim, na conclusão de The Unity of Philosophical Experience (1937 [1999³]), se afirma que a filosofia é centrada na metafísica, sendo a história da metafísica uma sucessão de falhas em apontar 'o primeiro princípio do conhecimento humano' (GILSON, 1937 [1999³], pp. 254-5.). Esse tema é retomado nos dois livros fundamentais de Gilson sobre metafísica: L'être et l'essence (1948 $\left.\left[2008^{3}\right]\right)$ e Being and some philosophers $(1949)^{5}$. As primeiras linhas do primeiro são programáticas: "todas as dificuldades [échecs] da metafísica vêm de que os metafísicos substituíram o ser [être], como primeiro princípio de sua ciência, por um dos aspectos particulares do ser estudados pelas diversas ciências da natureza" (GILSON, 1948 [2008³], p. $9)^{6}$. Ora, esse ser, primeiro princípio da metafísica, é compreendido por Gilson fundamentalmente como um ser de existência, designando o próprio ato pelo qual um ente existe - o próprio ente, aliás, é um existente (op. cit., pp. 9-23). Assim, a história da metafísica é perpassada pelo erro de abandono do ser ou existir e o estudo de algo outro em seu lugar, de maneira que a metafísica mais digna desse nome será aquela que mais claramente se voltar para o ser enquanto ato de existência. Ora, argumenta Gilson, essa é precisamente a metafísica de Tomás de Aquino, pois não só ela se volta fundamentalmente para o próprio ser - esse / être / being - (cf. GILSON, 1960 [2005²], pp. 211), mas também

\footnotetext{
${ }^{5}$ Cf. a resenha deste segundo livro por Karl Löwith (1950).

${ }^{6}$ O papel desse tema do 'abandono do ser' na obra de Gilson é estudado por Pierre Aubenque (2009, pp. 5-18).
} 
considera esse ser como o ato de existir - acte d'exister / act of existing (GILSON, 1948 [2008³], pp. 81-123; 1949 [1952²] pp. 154-89). Em poucas palavras, "a metafísica tomística é existencial por direito" (GILSON, 1949 [1952²], p. 167). Enfim, o centro da filosofia cristã é uma consideração sobre o próprio ser enquanto existir e, se essa reflexão metafísica se dá na história, ela encontra seu ápice em Tomás de Aquino, que reflete precisamente sobre o ser existencial. Mais do isso, porém, Tomás retorna àquele termo inicial da filosofia cristã que é Deus mesmo, ao identificar o ser a Deus enquanto ato de existir (GILSON, 1948 [2008³], pp. 115-6 e 1949 [1952²], p. 178)! Enfim, Tomás de Aquino surge como a mais alta expressão da filosofia cristã tal como Gilson a lê na Aeterni Patris. A narrativa da história da filosofia, desse ponto de vista, será uma reiterada tentativa de apontar essa centralidade de Tomás de Aquino. Ao mesmo tempo, a relevância de cada autor para o desenvolvimento dessa história será estabelecida a partir de uma comparação entre suas doutrina e aquelas do Doutor Angélico ${ }^{7}$. Enfim, a filosofia cristã, necessariamente histórica, é o caminho para o que está além da história e quem mais se aproximou desse termo foi Tomás de Aquino.

III. Por esse rápido resumo de seu pensamento, vê-se o quão central é a metafísica na história da filosofia narrada por Gilson e que um pensador será tanto mais relevante para essa história quanto mais perto ele chegar da identificação entre ser e existência. O problema é que, embora Tomás de Aquino tenha "colocado tudo em seu devido lugar $\langle\ldots$..., ele dizia coisas tão obviamente verdadeiras que, de seu tempo até nosso dias, muito poucas pessoas foram suficientemente abnegadas para aceitá-las" (GILSON, 1937 [1999³], p. 49). Pois bem, o nosso Henrique de Gand estará naquele grupo maior, das pessoas que não aceitaram aquelas verdades apresentadas por Tomás... Isso porque um dos elementos fundamentais do pensamento de Henrique é, precisamente, a distinção entre ser e existência.

De fato, se nos voltarmos para a curta referência a Henrique que encontramos na primeira edição de La philosophie au moyen âge (1922, vol. 1, pp. 159-60), vemos que Gilson não faz mais do que apontá-lo como uma fonte de grande relevância para a compreensão da filosofia que se lhe sucede, representada principalmente por João Duns Escoto (c. 12651308). Ainda assim, Gilson não deixa de lembrar que Henrique se afasta veementemente da filosofia de Tomás de Aquino ao negar a identidade entre essência e existência (esse). Em poucas palavras, o Doutor Solene é considerado um seguidor do 'augustinismo' filosófico (augustinisme). Sem dúvida, não é muito aquilo que Gilson tem a dizer sobre Henrique nessa

\footnotetext{
${ }^{7}$ Uma interessante expressão desse método surge em GILSON, 1952 [2005²], p. 10.
} 
obra... Será necessário esperar textos mais tardios para uma descrição mais precisa e aprofundada da filosofia do Doutor Solene.

É isso precisamente que encontramos na segunda edição desse mesmo livro, publicada em 1944. Mais do que uma segunda edição, porém, esse é um outro livro completamente retrabalhado, principalmente porque Gilson, entre 1922 e 1944, elaborou de maneira muito mais aprofundada certos temas de seu pensamento, os quais se mostraram capitais para a sua narrativa da história da filosofia. Em primeiro lugar, como vimos há pouco, desde 1937 ele já defendia o caráter fundamental da metafísica para a reflexão filosófica; além disso, em suas obras de 1948 e 1949, ele torna sua tese mais exata ao apontar a centralidade do ser, o próprio ato de existir, como princípio primeiro da metafísica. Em segundo lugar (e isso ainda não foi mencionado aqui), em 1926, Gilson publica o artigo Pourquoi saint Thomas a critiqué saint Augustin, no qual ele expõe com mais clareza aquela escola que, segundo ele, é combatida por Tomás de Aquino no decorrer de toda sua obra, a saber: o augustinismo avicenizante. Arriscando um resumo grosseiro, os autores que caracterizam essa escola defendem, segundo Gilson, uma completa dependência direta do homem para com Deus no ato de intelecção; para ser mais preciso, segundo os defensores do augustinismo avicenizante, o intelecto agente não é senão Deus mesmo, restando ao homem uma completa passividade no ato de intelecção. Pois bem, é a partir dessa nova concepção de metafísica e da noção de augustinismo avicenizante que Gilson irá se voltar para Henrique de Gand na segunda edição de La philosophie au moyen âge.

Com isso, não surpreende que o estudo encontrado nessa nova edição da obra seja maior e mais preciso do que o anterior (GILSON, 1944 [20115], pp. 438-444). Como seria de se esperar, o fundamental é aqui para Gilson a metafísica e, em especial, a precedência da essência sobre a existência da metafísica de Henrique de Gand. De fato, ele parece avaliar a metafísica do Doutor Solene principalmente como uma metafísica acerca de essências e não como uma metafísica do ser tomado como ato de existir. Assim, na metafísica de Henrique, o próprio ser compartilha o papel de princípio do conhecimento humano com as noções de necessidade (necesse) e de coisa (res). Estas duas são concebidas em sua metafísica como próprias das essências e não do existente. Assim, a necessidade se dá propriamente no âmbito da essência, sendo o existente contingente; a noção de coisa, igualmente, é concebida por Henrique como algo na medida em que é cognoscível e não como algo existente (op. cit., p. 440). Ou seja, na interpretação de Gilson, as três principais noções filosóficas na metafísica de Henrique dizem respeito antes às essências do que ao que existe. Enfim, o ser da metafísica do Doutor Solene é, antes de tudo, o ser de essência e não o ser de existência, o que o afasta fundamentalmente de Tomás de Aquino. A isso, Gilson adiciona a tendência de 
Henrique de enfatizar a papel fundamental da ação de Deus no ato humano de conhecimento da verdade. Dessa maneira, Henrique defende uma filosofia na qual todo conhecimento verdadeiro só pode partir da consideração do próprio ser essencialmente necessário e se atualizar com o auxílio da inteligência agente que é o próprio Deus (op. cit., p. 443). Em poucas palavras, Henrique produz uma filosofia que reúne uma metafísica de essências com uma reflexão sobre o conhecimento humano muito próxima a um augustinismo avicenizante ${ }^{8}$.

Essa é a mesma leitura que Gilson manterá quando retornar ao pensamento de Henrique de Gand na sua History of Christian Philosophy (1955). Nesse seu último estudo sobre o Doutor Solene, Gilson é profundamente influência por dois estudos de seu aluno, Jean Paulus. Com efeito, embora ambos já tivessem sido publicados em 1944 e sejam citados por Gilson na segunda edição de La philosophie au moyen âge (1944, pp. 447-8), Gilson parece só ter adotado as conclusões desses estudos em sua história da filosofia cristã de 1955 . O primeiro texto de Paulus a que nos referimos é o artigo Henri de Gand et l'argument ontologique (1935); o segundo é sua tese Henri de Gand: essai sur le tendances de la métaphysique, publicada em 1938, orientada e prefaciada pelo próprio Gilson (PAULUS, 1938, pp. vii-x). O principal elemento que Gilson herda dessas duas obras de Paulus é a afirmação de uma necessária precedência da discussão sobre conhecimento humano com relação à metafísica na obra de Henrique. De fato, como Paulus deixa claro em seu artigo e sua tese, não há como compreender a metafísica do Doutor Solene sem uma consideração prévia da sua doutrina da intelecção e da ciência. Isso, segundo Paulus, é claramente visto nas obras teológicas de Henrique. Ao que parece, é precisamente influenciado por essa leitura que Gilson inverte a ordem de seu estudo sobre Henrique na History of Christian Philosophy (1955, pp. 447-454) e, em lugar de partir da metafísica para chegar à doutrina da intelecção (como fazia em 1944), prefere iniciar seu estudo de Henrique pela consideração - bem mais precisa e detalhada, diga-se de passagem - de sua doutrina da intelecção (op. cit., pp. 447-8), para somente em seguida chegar ao estudo de sua metafísica, ainda tomada como fundamentalmente voltada para essências e não para a existência (op. cit., pp. 448-52). Ao final da passagem, Gilson retorna mais uma vez ao problema da intelecção para enfatizar, como fazia já em 1944, a necessidade apontada por Henrique de um auxílio divino para o conhecimento da verdade pelo intelecto humano (op. cit., pp. 452-4).

\footnotetext{
${ }^{8}$ Poucos anos depois, em 1950, Frederick Copleston defende uma leitura semelhante no segundo volume da sua History of Philosophy, classificando a metafísica de Henrique como "a metaphysic of the intelligible, a metaphysic of the essences, rather than of the concrete" $\left(1950\left[1993^{3}\right]\right.$, p. 473) e apontando, igualmente, o fato de Gilson ligar o Doutor Solene ao augustinismo avicenizante (op. cit., p. 474).
} 
IV. Como podemos ver, a evolução da leitura que Gilson propõe da obra de Henrique de Gand nesses três excertos é clara. Ele parte da quase desconsideração do Doutor Solene em sua história da filosofia medieval, para uma leitura aprofundada do pensamento teológico e filosófico deste último. O mais interessante, porém, é o fato de essa mudança poder ser diretamente relacionada a desenvolvimentos na pensamento do próprio Gilson e, igualmente, de outros pesquisadores associados a ele, como Paulus. Ao fim, notamos que, se a leitura de Henrique de Gand não foi fundamental para o desenvolvimento da obra de Gilson, ela certamente foi influenciada pelo desenvolvimento daqueles elementos que, em sua filosofia, foram de fato centrais.

Bibliografia:

AUBENQUE, P. Faut-il déconstruire la métaphysique?. Paris: PUF, 2009.

BOURKE, V. J. "Aeterni Patris, Gilson and Christian Philosophy". Proceedings of the American Catholic Philosophical Association 53 (1979), pp. 5-15.

COPLESTON, F. History of Philosophy. Vol. 2: Medieval Philosophy. New York: Doubleday, $1950\left[1993^{3}\right]$.

GILSON, É. La philosophie au moyen âge. 2 vols. Paris: Payot, 1922.

"Pourquoi saint Thomas a critiqué saint Augustin". Archives d'histoire doctrinale et littéraire du moyen âge (1926-7), pp. 5-127.

$\left[1999^{3}\right]$ The Unity of Philosophical Experience. San Francisco: Ignatius Press, 1937 Héloïse et Abélard. Paris: Vrin, 1938 [1997³]. . L'être et l'essence. Paris: Vrin, 1948 [2008³].

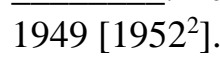

Being and some philosophers. Toronto: Pontifical Institute of Mediaeval Studies, La philosophie au moyen âge. Paris: Payot, 1944 [20115].

$\left[2005^{2}\right]$

Jean Duns Scot. Introduction à ses positions fondamentales. Paris: Vrin, 1952 History of Christian Philosophy in the Middle Ages. New York: Random House, 1955. Le philosophe et la théologie. Préface de J.-F. Courtine. Paris: Vrin, 1960 [2005²]. HENRICI GANDAVENSIS. Summae Quaestionum Ordinariarum (...). In aedibus Badii 
Ascen- sii, 1529. Edition in 2 vols. St. Bonaventure: The Franscican Institute, 1953.

Quodlibeta Magistri Henrici Goethals a Gandavo Doctoris Solemnis: Socii Sorbonici: et ar- chidiaconi Tornacensis cum duplici tabella. 2 vols. Vaenundantur ab Iodoco Badio Ascensio, Paris, 1518. Edition in 2 vols. Louvain: Bibliothèque S. J., 1961.

HENRICI DE GANDAVO. Opera omnia. Ed. G. A. Wilson et al. De Wulf-Mansion Centre, Ancient and Medieval, series 2. Louvain: Leuven UP, 1979-.

LEÃO XIII. "Littera encyclica Aeterni Patris". In: THOMAS AQUINAS. Opera omnia. Vol. I. Iussu impensaque Leonis XIII P. M. edita. Romae: Ex Typographia Polyglotta, 1882, pp. iii-xvi.

LÖWITH, K. "Book review of: GILSON, ETIENNE. Being and Some Philosophers; MARCEL, GABRIEL. The Philosophy of Existence; and KUHN, HELMUT. Encounter with Nothingness". Social Research 17.1 (1950), pp. 128-34.

PAULUS, J. "Henri de Gand et l'argument ontologique". Archives d'histoire doctrinale et littéraire du moyen âge (1935-6), pp. 265-323.

Henri de Gand: essai sur les tendences de sa métaphysique. Paris: Vrin, 1938.

VIGNAUX, P. Philosophie au moyen âge précédé d'une Introduction nouvelle et suivi de Lire Duns Scot aujourd'hui. Albeuve: Castella, 1987. 